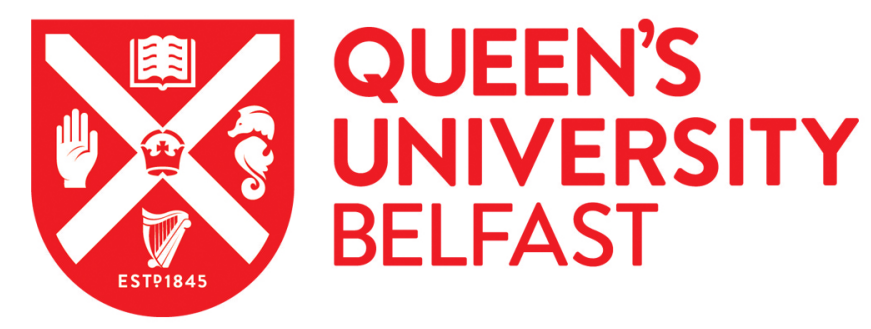

\title{
GPR Profile of Beacon Valley, Dry Valleys, Antarctica: Analysis of the GPR Response from Rocky Permafrost
}

Nobes, D. C., Sletten, R. S., Bannister, M. T., \& Godfrey, M. J. (2018). GPR Profile of Beacon Valley, Dry Valleys, Antarctica: Analysis of the GPR Response from Rocky Permafrost. In 17th International Conference on Ground Penetrating Radar (GPR 2018): Proceedings [8441595] (International Conference on Ground Penetrating Radar (GPR): Proceedings). Institute of Electrical and Electronics Engineers Inc. https://doi.org/10.1109/ICGPR.2018.8441595

Published in:

17th International Conference on Ground Penetrating Radar (GPR 2018): Proceedings

Document Version:

Peer reviewed version

Queen's University Belfast - Research Portal:

Link to publication record in Queen's University Belfast Research Portal

\section{Publisher rights}

(C) 2018 IEEE.

This work is made available online in accordance with the publisher's policies. Please refer to any applicable terms of use of the publisher.

\section{General rights}

Copyright for the publications made accessible via the Queen's University Belfast Research Portal is retained by the author(s) and / or other copyright owners and it is a condition of accessing these publications that users recognise and abide by the legal requirements associated with these rights.

Take down policy

The Research Portal is Queen's institutional repository that provides access to Queen's research output. Every effort has been made to ensure that content in the Research Portal does not infringe any person's rights, or applicable UK laws. If you discover content in the Research Portal that you believe breaches copyright or violates any law, please contact openaccess@qub.ac.uk. 


\section{GPR Profile of Beacon Valley, Dry Valleys, Antarctica: Analysis of the GPR Response from Rocky Permafrost}

\author{
David C. Nobes \\ School of Geophysics and Measurement-Control Technology \\ East China University of Technology \\ Nanchang 330013, Jiangxi, China \\ david.nobes@canterbury.ac.nz
}

Ronald S. Sletten

Department of Earth Sciences

University of Washington

Seattle, Washington, USA

sletten@u.washington.edu

\author{
Michele T. Bannister \\ Astrophysics Research Centre \\ School of Mathematics and Physics \\ Queen's University Belfast \\ Belfast, Northern Ireland, United Kingdom \\ Myfanwy J. Godfrey \\ Raine \& Associates \\ Level 23, 127 Creek Street \\ Brisbane, Queensland 4000, Australia
}

\begin{abstract}
Results of ground penetrating radar (GPR) profiling of Beacon Valley in Antarctica suggests that significant quantities of ice are present. A more detailed analysis of widespread diffractions highlights the large variations in the GPR velocity, both laterally and with depth. The dominant aspect of the data is the strong layering of the velocity, with high velocities $(0.13 \mathrm{~m} / \mathrm{ns}$ or greater) in the upper approximately $200 \mathrm{~ns}$ (about 13 metres) and low velocities $(0.11 \mathrm{~m} / \mathrm{ns}$ or less) below. The most striking feature is a near vertical zone of low velocities, as low as 0.07 $\mathbf{m} / \mathbf{n s}$, which appears as a set of diffractions that are "stacked" one above another. Such a structure is interpreted as a largerthan-normal crack formed in permafrost polygonal patterned ground or possibly a relict crevasse.
\end{abstract}

Keywords-ground penetrating radar; Antarctica; Dry Valleys; Beacon Valley; permafrost

\section{INTRODUCTION}

The Dry Valleys of Antarctica are a proxy for features and processes we observe on Mars [1, 2], and Beacon Valley is one of the Dry Valleys of Antarctica (Fig. 1). The presence of massive ice in Beacon Valley was proposed and documented previously [3, 4], and has an obvious effect on the ground penetrating radar (GPR) response [5, 6, 7]. Our results from Beacon Valley highlight variations in the GPR response (Fig. 2 ), especially when plotted using both automatic gain control (AGC) and spreading and exponential compensation (SEC).

When the GPR data are more deeply analyzed, we note significant differences in the subsurface structure, both laterally and with depth. The shallow subsurface, less than about 200 ns or about $13 \mathrm{~m}$, is characterized by high velocities. The deeper subsurface, in contrast, is characterized by low velocities. We also see near vertical or steeply dipping anomalous features which could be large cracks or relict crevasses.

\section{Site DESCRIPTION AND SURVEY DESIGN}

\section{A. Beacon Valley}

Beacon Valley is located in the southwest sector of the McMurdo Dry Valleys (Fig. 1), a hyper-arid polar desert

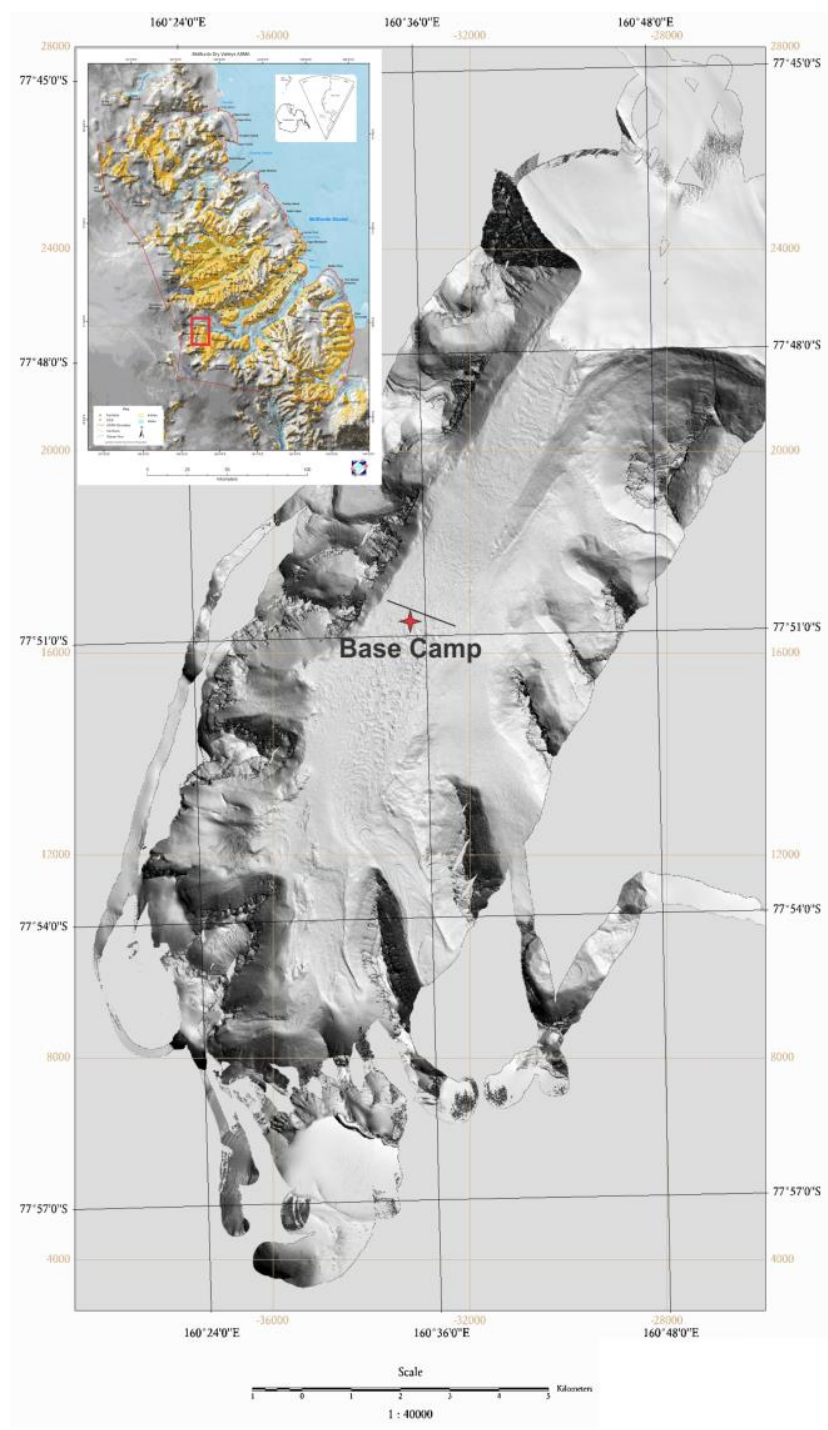

Fig. 1 Beacon Valley digital terrain at $2 \mathrm{~m}$ resolution and illuminated from the southwest. The approximate locations of the Base Camp (star) and the transect are indicated. Inset: Location of Beacon Valley (box) in the Dry Valleys and (second inset) of the Dry Valleys in Antarctica. 
adjacent to the Ross Sea. The area, as already noted, is a proxy for conditions on Mars, and so has been much studied. Of particular interest are the geometric features common in permafrost regions, the polygonal patterned ground (PPG). Our work on imaging the polygons has been previously reported [7].

\section{B. GPR Transect}

The 1300-m long GPR transect was located near the centre of Beacon Valley (Fig. 1), and oriented almost east-west. The profile began at the eastern margin on a lateral moraine which was clearly distinguishable from valley floor material. 30 to 40 metres to the west was a gradual transition to larger rocks, predominantly weathered red-brown basalt with scattered sandstones, typical of the valley floor (Fig. 2). The transect then passed through five relatively evenly spaced, roughly bowl-shaped sinkholes, each between forty and a hundred metres across and between ten and thirty metres deep, before passing into flattish terrain at about $850 \mathrm{~m}$. This continued until a slight $3 \mathrm{~m}$ deep shallowly sloping depression at the end.

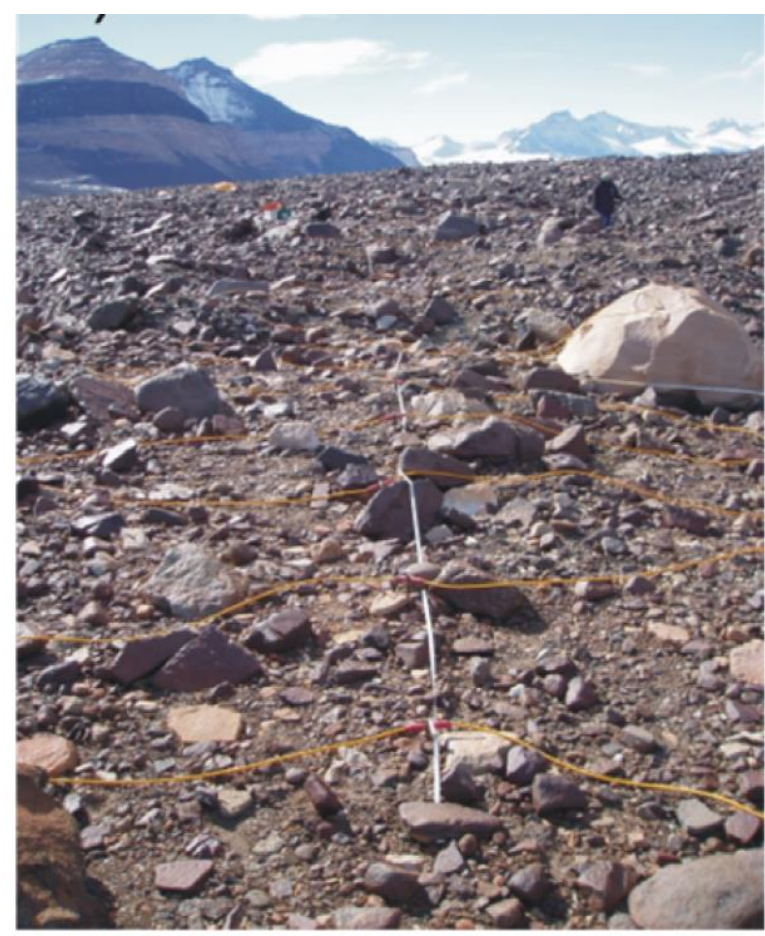

Fig. 2. Typical terrain along the Beacon Valley GPR transect.

The data were acquired using a pulseEKKO 100A system in $100 \mathrm{~m}$ segments. The central antenna transmitting frequency was $50 \mathrm{MHz}$, and the common offset step size was $0.5 \mathrm{~m}$ (50 $\mathrm{cm}$ ) using a 2-m antenna separation. Processing was done both segment by segment, and on the whole merged profile. There were occasional noise spikes, which were minimized using median filters. Initial processing used the same velocities as were observed for Victoria Valley, $0.13 \mathrm{~m} / \mathrm{ns}$ [5, 6, 7]. However, more recent analysis of diffractions in the Beacon Valley profile suggests a velocity of $0.12 \mathrm{~m} / \mathrm{ns}$ may be more appropriate.

\section{Detailed ANALYSIS AND PROCESSING}

\section{A. Velocity Variations}

The Beacon Valley GPR profile was analysed for velocity variations by fitting hyperbolas to 257 diffractions across the profile. Each 100-m segment was analysed separately. Of the 13 segments, sections $2(100-200 \mathrm{~m}$ along the profile) and 11 $(1000-1100 \mathrm{~m})$ had the fewest diffractions, 12, whereas section $1(0-100 \mathrm{~m})$ had the most, 30 . The overall average velocity was $0.123 \mathrm{~m} / \mathrm{ns}$ with a standard deviation of \pm 0.023 $\mathrm{m} / \mathrm{ns}$; the median value $0.120 \mathrm{~m} / \mathrm{ns}$. Section 2 had the highest mean (0.138) and median (0.143) velocities; section 5 had the lowest mean (0.109) and median (0.110). Each section was then migrated using the velocity determined for that section. The resulting migrated sections were then merged. There are small misfits at the boundaries of each section, but they are not as serious as having sections either under- or over-migrated.

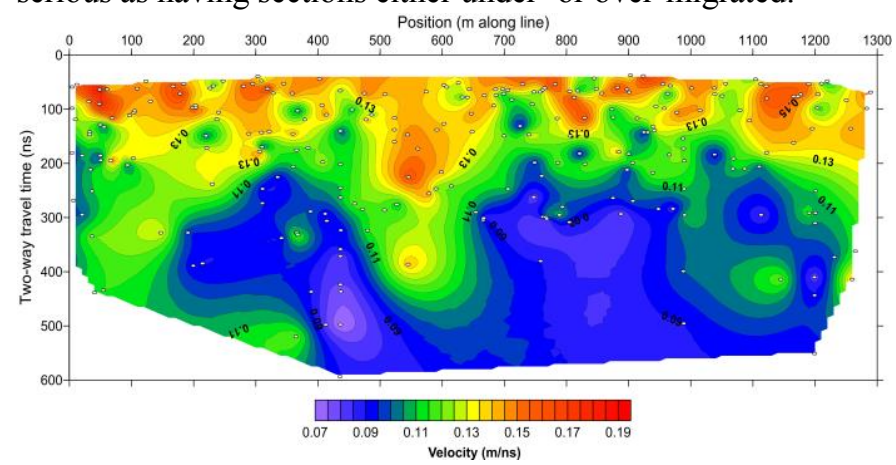

Fig. 3. Beacon Valley profile velocity variations. Note the stratified appearance and the anomalies at about $110,435,550$, and $1150 \mathrm{~m}$ along the profile. The colour bar scale is the velocity in $\mathrm{m} / \mathrm{ns}$.

The velocity varies laterally and with depth (Fig. 3), but we need to remember that the diffractions are threedimensional features that can arise from any direction, so the results need to be considered with caution. That said, there are two striking features apparent: the first is the stratified nature of the velocity. The shallow velocities, for two-way travel times (TWTs) less than about $200 \mathrm{~ns}$, tend to be greater than $0.13 \mathrm{~ms} / \mathrm{ns}$, whereas the deeper velocities tend to be less. The other feature is the nearly vertical low velocity anomaly at about $430 \mathrm{~m}$ along the profile. There are also some high velocity anomalies apparent in Fig. 3, at 110, 550, and $1150 \mathrm{~m}$ along the profile, but they are based only on 1 point in each case. There are a number of points that comprise the anomaly at $435 \mathrm{~m}$, based on a stack of diffractions of the sort that might occur because of a large crack or crevasse.

We can test the presence of the low velocity feature by examining the data when the entire profile is migrated using a higher velocity. A detail from the segment between 340 and 520 $\mathrm{m}$ shows a set of stacked "smiles" at about the $435 \mathrm{~m}$ mark (Fig. 4, next page), consistent with low velocity diffractions migrated using too high a velocity. Thus, we can conclude that the feature at $435 \mathrm{~m}$ is indeed a low-velocity feature. 


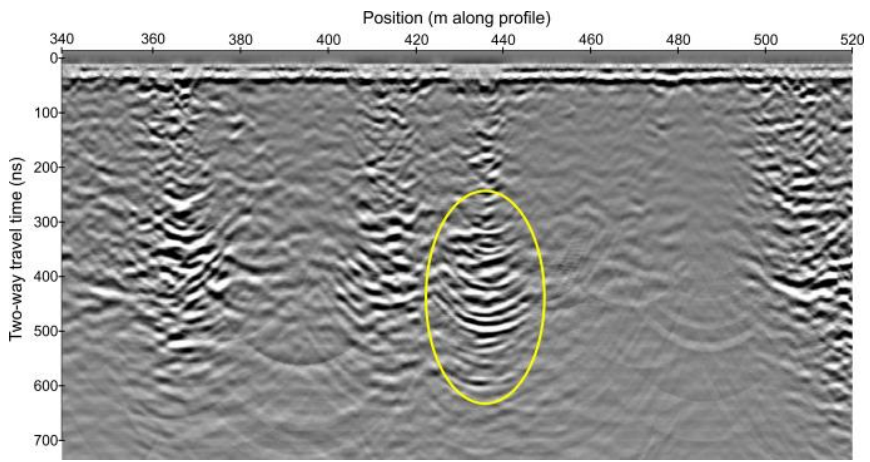

Fig. 4. Detail from Beacon Valley profile migrated at $0.120 \mathrm{~m} / \mathrm{ns}$. Note the stacked "smiles" (circled) at about $435 \mathrm{~m}$ along the profile.

\section{B. Structural Features}

Each separate 100-m segment was migrated using a median velocity that was appropriate for that section (Table 1). The median was used because it is more robust and less sensitive to outliers. There are minor mismatches at the boundaries between segments when they are merged into one, but in most cases the mismatches are insignificant. Once the segments are merged, then we can do an interpretation of the features present.

Some of the features will have correlative surface topographic features. However, initially we want to compare the migrated merged profile with the velocity variations, which we would also expect to have some correlations. Unfortunately, it is difficult to include topography with the velocity variation plots, so initially we will examine the velocity-subsurface feature correlations, then look at how those features correlate with the topographically corrected migrated merged profiles.

TABLE I. SEgment Velocities

\begin{tabular}{|c|c|c|c|c|}
\hline \multirow{2}{*}{ Segment } & \multicolumn{4}{|c|}{ Velocities (m/ns) } \\
\cline { 2 - 5 } & $\begin{array}{c}\text { Number of } \\
\text { Diffractions }\end{array}$ & Mean & $\begin{array}{c}\text { Standard } \\
\text { Deviation }\end{array}$ & Median \\
\hline $0-100$ & 30 & 0.125 & 0.025 & 0.120 \\
\hline $100-200$ & 12 & 0.138 & 0.023 & 0.143 \\
\hline $200-300$ & 14 & 0.131 & 0.019 & 0.130 \\
\hline $300-400$ & 26 & 0.120 & 0.022 & 0.120 \\
\hline $400-500$ & 26 & 0.109 & 0.024 & 0.110 \\
\hline $500-600$ & 14 & 0.138 & 0.013 & 0.140 \\
\hline $600-700$ & 20 & 0.127 & 0.017 & 0.130 \\
\hline $700-800$ & 24 & 0.115 & 0.022 & 0.115 \\
\hline $800-900$ & 20 & 0.122 & 0.026 & 0.120 \\
\hline $900-1000$ & 27 & 0.120 & 0.020 & 0.120 \\
\hline $1000-1100$ & 12 & 0.126 & 0.018 & 0.128 \\
\hline $1100-1200$ & 15 & 0.135 & 0.022 & 0.140 \\
\hline $1200-1300$ & 17 & 0.117 & 0.022 & 0.115 \\
\hline $0-1300$ & 257 & 0.123 & 0.120 & 0.023 \\
\hline
\end{tabular}
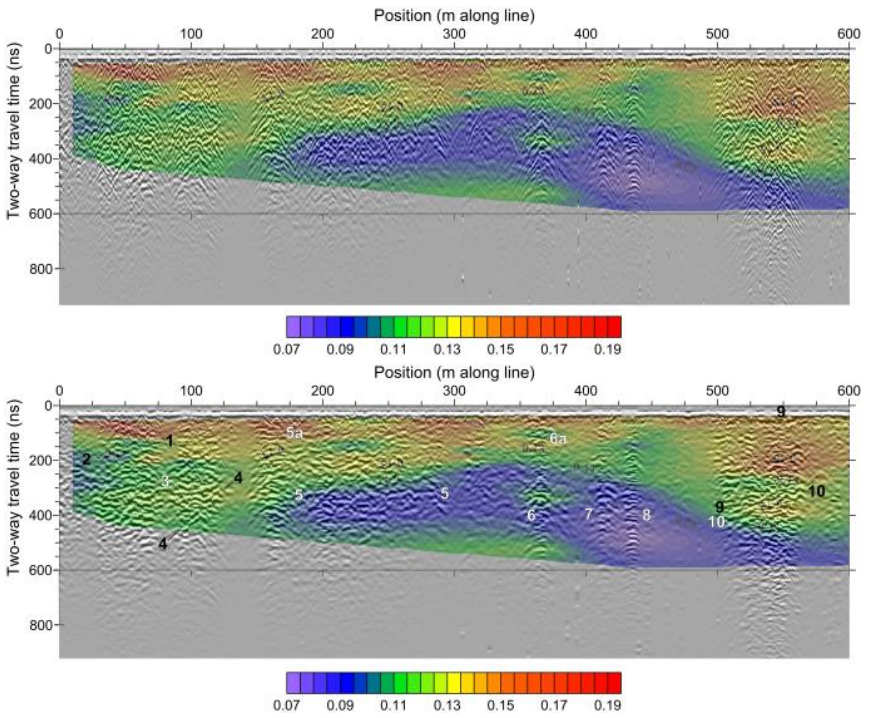

Fig. 5. Unmigrated merged (top) and migrated merged (bottom) profiles from 0 to $600 \mathrm{~m}$, overlain by velocity variations.

The profile is too long to clearly see significant features, so the overlay of the velocity with the first 7 merged segments $(0$ to $600 \mathrm{~m}$ ) are shown in Figure 5 (above). The unmigrated (top) and migrated (bottom) sections are both plotted for comparison. Major features are numbered so that the features are not obscured by any lines or circles. Many features are close to each other, which suggests some relationships or interactions between them. For example, features 1 and 2 (far left) appear to merge or cross between 60 and $80 \mathrm{~m}$ along the line. The individual features are discussed more in the next section.

\section{Complex Attributes}

In order to highlight the features that have some continuity, we use complex attributes [8,9]. To summarise, the envelope (instantaneous amplitude) reflects changes in reflection strength, and is often associated with changes in lithology and sequence boundaries [8]; the instantaneous phase emphasises the continuity of reflection events [8]; and the instantaneous frequency provides a correlation tool [8] that can change depending on such factors as bed thickness changes.

The envelope (Fig. 6) has the clearest features and we will focus on those. We first note that the envelope responses often align with boundaries in the velocities, which is not surprising. The same features labelled in the migrated section in Fig. 5 are again labelled in Fig. 6 to test their persistence (and most do) from one mode of processing and presentation to the next.

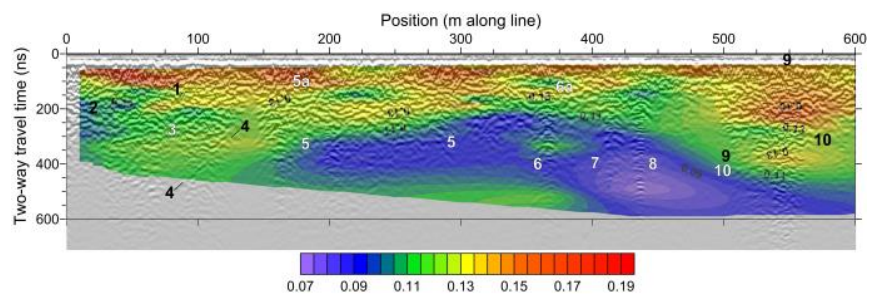

Fig. 6. Detail from Beacon Valley envelope profile. Note how many of the velocity boundaries correspond with strong reflection amplitudes. 
We would expect a number of these features to be present and perhaps clearer when topography is added (Fig. 7). Feature 1 (top left, Fig. 7) appears to be the top of a less reflective sequence in the migrated profile, and may continue as a relatively planar reflection that links up with feature 3 and continues across as far as feature 6 , where it abruptly ends. Feature 2 appears to be related to feature 1, and is the basal reflection of the less reflective sequence, which is correlated with the initial lateral moraine at the start of the profile.

Features 3 and 5 (not labelled) include the continuation of feature 1, but also include some relatively horizontal undulating reflections that are part of the complex stratigraphy of the first part of the sequence beyond the lateral moraine. The reflection at about 300 ns two-way travel time (TWT) appears to merge with or cut across the dipping reflection from feature 1 .

Feature 4 appears to be structural in nature, and may either be a crack associated with the first significant hollow at about $140 \mathrm{~m}$ along the profile, or a fault that developed during sublimation contraction of the surface and near surface. It does not appear to disrupt or offset any of the undulating reflections associated with features 3 and 5 .

Features 6,7 , and 8 are vertical or nearly vertical, and may be associated with sublimation cracking that is part of the PPG topography. Features 6 and 7 appear to extend from the surface to depth. In contrast, feature 8 is a low-velocity feature noted previously and does not appear to reach the surface, but rather is restricted to times greater than about 400 ns TWT or depths greater than about $25 \mathrm{~m}$ below the zero reference. There does appear to be a small surficial dip or crack at the surface, but the crack does not connect with the deeper low-velocity anomaly.

Feature 9 is another structural element, similar to feature 4. It is difficult to tell if it disrupts of offsets any of the complex stratigraphy. Feature 10 (labelled by an arrow at the right-hand margin of the profiles in Fig. 7) was the apparently stratigraphic element noted in Figs. 5 and 6, but here it is weaker and less obviously part of the stratigraphy. Instead, there is a shallower feature (arrow on the margin above 10) that appears to be a shallowly dipping feature similar to features 1,3 , and 5 at the beginning and middle of the profile.

Additional features not noted in Figs. 5 or 6 are labelled A, B, C, and D in Fig. 7. Like features 4 and 9, they appear to be structural in nature, but unlike 4 and $9, \mathrm{~A}, \mathrm{~B}$, and $\mathrm{C}$ have no clear relationship to any significant surface features. A may have an associated surface dip at about $190 \mathrm{~m}$ along the line, and $\mathrm{B}$ may be an adjunct to feature 4 . D is akin to 4 and 9, in that it appears to be associated with the margin of one of the hollows encountered along the profile.

\section{Discussion OF RESUlts}

The laterally continuous reflection that may include features 1, 2, 3, and 5, cuts across other uneven discontinuous reflections that may be permafrost or relict glacial features. Because of its relatively planar nature and its continuity, it may represent a phase transition, or a relict boundary. Only
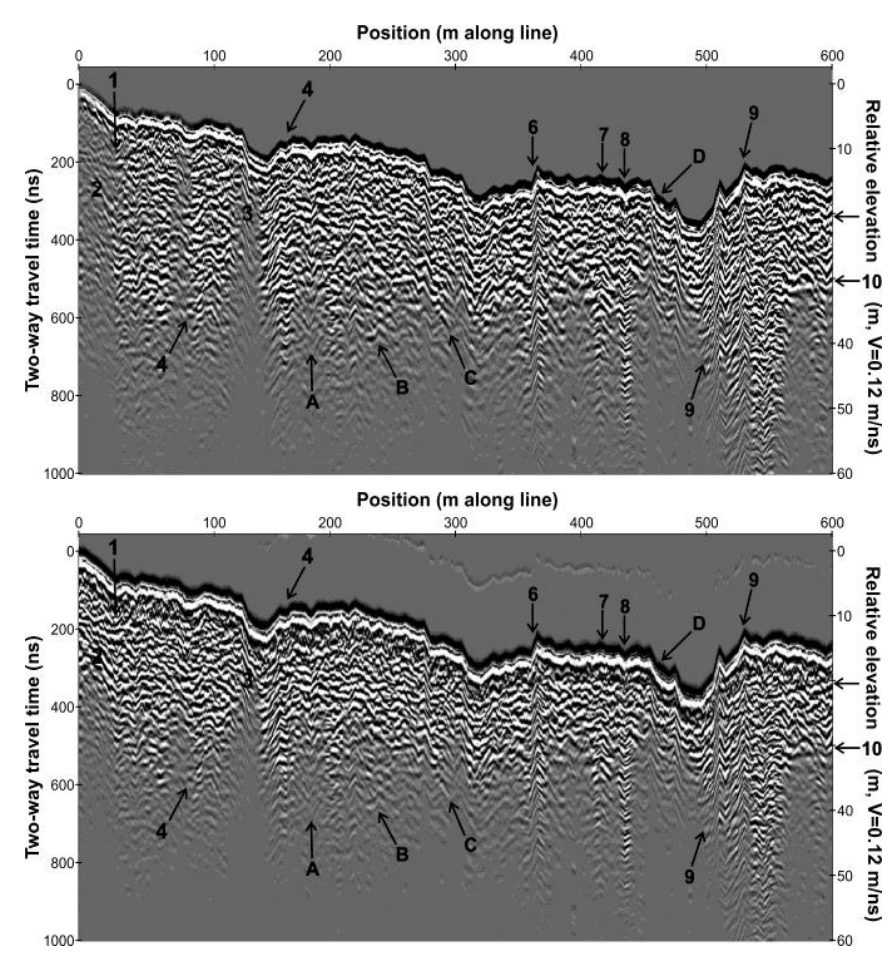

Fig. 7. Topography-corrected migrated (top) and envelope (bottom) profiles.

direct invasive sampling can resolve the question.

The structural features are of two types: 1. dipping features 4,9 , and possibly B associated with the margins or boundaries of hollows that may in turn be large permafrost polygonal patterned ground (PPG) features; and 2. vertical or near-vertical features $6,7,8$, and possibly $A$, that may be cracks or relict cracks within PPG topographic highs. Feature $\mathrm{C}$ is a dipping feature, not vertical or near-vertical, is not associated with any of the margins of the large hollows, and has no clear surface expression above it. It remains enigmatic.

Because of their positions at the margins of the hollows, the dipping structural features may be current sublimation cracks associated with PPG formation, or may be the remains of past activity. The near-vertical features, on the other hand, may be cracks that started to form or are starting to form, but did not or have yet to fully develop.

Finally, the low velocity anomaly is associated with the near-vertical feature 8 , but it is not connected to the surface. As with the laterally continuous reflection mentioned earlier, only direct invasive sampling may resolve the nature of the low velocity anomaly. It is unlikely to be due to free water in the subsurface. Beacon Valley is a cold, high elevation, hyperarid polar desert valley.

The other half of the profile is less complex in nature, and includes a broad flat region from about $800 \mathrm{~m}$ along the profile to the end at $1300 \mathrm{~m}$, and so has not been discussed in detail here. There are far fewer anomalous features. There may be a laterally continuous boundary and a few structural features, but there are no hollows or significant surface cracks for correlation or association. 
The high velocity upper layer is likely a mixture of ice and rock. The velocities, greater than $0.13 \mathrm{~m} / \mathrm{ns}$, are consistent with such a mixture. The nature of the basal low-velocity zone is unknown, but the high altitude and hyper-aridity of Beacon Valley would suggest that water is not present in any significant amounts. Possible candidates would be fine-grained material of either morainal or basal glacial origins.

\section{CONCLUSIONS}

The GPR response from a long profile in Beacon Valley, situated in the McMurdo Dry Valleys of Antarctica, was reanalysed and shows strong velocity variations. There is significant vertical variability, consistent with a high-velocity ice and rock mixture overlying a low velocity medium. The nature of the basal low-velocity zone is undetermined.

In addition to the strong stratification of the velocity, there are vertical to near-vertical anomalous features where the velocities are higher or lower than the surrounding layer. The high velocity features tend to be limited in scope and are often defined by only one or two anomalous points, and thus may be open to question.

One near-vertical low-velocity anomaly, however, is clear and well defined. As with the velocity stratification, the nature of this low-velocity anomaly is undetermined. It may be an old contraction crack infilled with fine-grained material. As noted earlier, water in any significant quantities is unlikely.

\section{ACKNOWLEDGEMENT}

The research was in part supported by Antarctica New Zealand, who also provided logistical support, the United States Antarctic Program and the National Science Foundation, and by the Department of Geological Sciences and the Mason Trust at the University of Canterbury. Prof.
Jamie Sulmeister and the excellent Scott Base staff provided invaluable help during the field season, and the incomparable Jon Lapwood provided field assistance.

\section{REFERENCES}

[1] W.W. Dickinson and M.R. Rosen, "Antarctic permafrost: An analogue for water and diagenetic minerals on Mars," Geology, vol. 31(3): pp. 199-202, 2003.

[2] R.S. Sletten, B. Hallet and R. C. Fletcher, "Resurfacing time of terrestrial surfaces by the formation and maturation of polygonal patterned ground," J. Geophys. Res., vol. 108(E4): pp. 8044-8053, doi: 10.1029/2002JE001914, 2003.

[3] D.R. Marchant, A.R. Lewis, W.M. Phillips, E.J. Moore, R.A. Souchez, G.H. Denton, et al., "Formation of patterned ground and sublimation till over Miocene glacier ice in Beacon Valley, southern Victoria Land, Antarctica," GSA Bulletin, vol. 114(6): pp. 718-730, 2002.

[4] F. Ng, B. Hallet, R.S. Sletten, and J.O. Stone, "Fast-growing till over ancient ice, Beacon Valley, Antarctica," Geology, vol 33(2): pp. 121124, 2005.

[5] M.T. Bannister, "Polygonal patterned ground and ancient buried ice on Mars and in Antarctica," unpublished B.Sc. (Honours) project in Astronomy and Geology, Department of Geological Sciences and Department of Physics and Astronomy, University of Canterbury, 2007.

[6] M.J. Godfrey, "2D and 3D Geophysical Imaging of Polygonal Patterned Ground in the McMurdo Dry Valleys, Antarctica," M.Sc. thesis, Department of Geological Sciences, University of Canterbury, 2008.

[7] M.J. Godfrey, M.T. Bannister, D.C. Nobes, and R.S. Sletten, "3D timelapse imaging of polygonal patterned ground in the McMurdo Dry Valleys of Antarctica," in Proceedings of GPR2008: 12th International Conference on Ground Penetrating Radar, Birmingham, UK.

[8] M. T. Taner, F. Koehler, and R. E. Sheriff, "Complex seismic trace analysis”. Geophysics, vol. 44: pp. 1041 - 1063, 1979.

[9] D. C. Nobes and H.M. Jol, "Enhancing form and structure: Complex attributes as aids for ground penetrating radar interpretation", in Proceedings of the 2nd Near-Surface Asia Pacific Conference, Waikoloa, Hawaii, Ground Penetrating Radar Session Paper 6. doi: 10.1190/NSAPC2015-082. 